\title{
Uma sugestão de atividade com enfoque CTS nas aulas de matemática
}

\section{A suggested approach CTS activity contributing to the process of teaching mathematics}

\author{
Ana Cristina Schirlo ${ }^{1}$; Sani de Carvalho Rutz da Silva ${ }^{2}$
}

\section{Resumo}

Este trabalho, com enfoque Ciência, Tecnologia e Sociedade, apresenta o desenvolvimento do projeto “Apagão, outra vez?", que tinha por objetivo, alertar os estudantes que a energia elétrica é relevante para o modo de se viver neste século XXI. Os sujeitos deste projeto foram estudantes do nono ano do Ensino Fundamental de uma escola estadual localizada na cidade de Ponta Grossa no Estado do Paraná. Cabe apontar que, no decorrer do projeto, os dados foram coletados por meio de registros diários feitos pela pesquisadora, de registros feitos pelos estudantes e de conversas individuais e coletivas, gravadas em áudio. E que a sua análise teve cunho qualitativo. De modo geral, as atividades realizadas no decorrer do projeto foram relevantes, pois permitiram uma reflexão sobre a vivência do estudante, enfocando os conceitos de energia envolvidos no seu dia a dia. Assim, professores de outras áreas do saber podem se apropriar deste projeto e desenvolvê-lo com objetivos próprios de seu conteúdo.

Palavras-chave: CTS. Ciência. Tecnologia. Sociedade. Aulas de matemática.

\begin{abstract}
This work, focusing Science, Technology and Society, presents the development of the project "Blackout, again?" Which was intended to alert students that electricity is relevant to the way of living in this century. The subjects of this project were students of the ninth year of elementary school to a public school located in the city of Ponta Grossa in Paraná State. It should be noted that in the course of the project, data were collected through daily records made by the researcher, records made by students and individual and collective conversations, audio taped. And that their analysis was qualitative. In general, the activities performed during the project were relevant because they allowed a reflection on the experience of the student, focusing on the concepts of energy involved in their day-to-day. Thus, teachers of other disciplines can take ownership of this project and develop it with goals of their own content.
\end{abstract}

Keywords: CTS. Science. Technology. Society. Mathematics classes.

\footnotetext{
${ }^{1}$ Mestre em Ensino de Ciência e Tecnologia (UTFPR/PG), graduada em Matemática(UEPG), professora efetiva da Secretaria de Estado da Educação do Paraná, na área de Matemática e Física. Email: acschirlo@bol.com.br

${ }^{2}$ Graduada Matemática pela Universidade Estadual de Ponta Grossa, mestre em Matemática Aplicada pela Universidade Federal do Rio Grande do Sul e doutora em Ciência dos Materiais (Instituto de Física, Instituto de Quimica e Escola de Engenharia Metalurgica) pela Universidade Federal do Rio Grande do Sul . Atualmente é professor da Universidade Tecnológica Federal do Paraná.Email: sani@utfpr.edu.br
} 


\section{Introdução}

É fato que a humanidade tem vivenciado mudanças em todas as áreas. Por exemplo, na educação, na medicina, na telecomunicação, na informática, entre outras. Esta afirmativa é facilmente comprovada. Atualmente, informações, imagens e/ou sons cruzam oceanos em poucos segundos, fazendo com que o mundo os receba em tempo real.

Nesse contexto, entende-se que a tecnologia está intrinsecamente presente no cotidiano das pessoas. Marcuse (1999, p. 21) expõe que, em face dos aspectos totalitários desta sociedade, não é mais possível falar em neutralidade da tecnologia. As transformações tecnológicas instigam o homem a mudar sua maneira de agir e de compreender o mundo.

Essa mudança pode depender dos diferentes olhares que o homem apresenta sobre a Era Tecnológica em que está inserido. Entretanto, o homem deve tomar cuidado para não se tornar dependente incondicional da doutrina da tecnologia.

Assim, a sociedade não deve apenas dominar técnicas, pois é relevante ir além de uma visão utilitarista dos produtos e transpor as análises técnicas que atualmente são empreendidas. Marx (1984, p. 424) já assinalava que a tecnologia, de um lado, "acumula a riqueza social e o domínio sobre a natureza; de outro, aumenta a alienação do trabalhador e acresce de mais-valia o capital".

Dessaforma,é interessante que o desenvolvimento científico e tecnológico esteja inserido no contexto social de maneira consciente, pois envolve o trabalho humano. Logo, é relevante ter uma visão menos alienada do mundo, promovendo debates sobre as diversas maneiras de se educar para o mundo tecnológico, bem como sobre os diversos procedimentos utilizados para atingir esta educação.

Nessa perspectiva, a tecnologia precisa ser entendida como um instrumento detentor de conhecimentos científicos, os quais deverão ser usados para amenizar as necessidades materiais do mundo globalizado. Sendo assim, a tecnologia não pode ser considerada apenas como uma mercadoria que se vende e que se compra, mas como um saber que se aprende e se incorpora no cotidiano do cidadão. Mas, para que isso ocorra, é necessário que as pessoas tenham consciência e conhecimento para se tornarem cidadãos críticos e reflexivos em relação ao desenvolvimento das inovações tecnológicas, preparados para usarem os artefatos tecnológicos.

Nesse interim, cabe aos educadores auxiliar os estudantes a se tornarem profissionais capazes de atuar com sucesso no mundo da Era Tecnológica. Diante desse desafio, questiona-se: Como proporcionar, aos estudantes, atividades que contribuam para sua formação crítica, nas tomadas de decisões, na Era Tecnológica?

\section{Ciência, Tecnologia e Sociedade}

É relevante apresentar o enfoque Ciência, Tecnologia e Sociedade (CTS) como um viés que possibilita tecer relações entre Ciência, Tecnologia e Sociedade, pois, segundo Bazzo et al (2003, p. 125), "os estudos CTS definem hoje um campo de trabalho recente e heterogêneo, ainda que bem consolidado, de caráter crítico a respeito da tradicional imagem essencialista da ciência e da tecnologia, e de caráter interdisciplinar por convergirem nele disciplinas como a filosofia e a história da ciência e da tecnologia."

Essa relação permite, tanto ao educador quanto ao educando, elaborar, desenvolver e promover discussões de relevância social no interior do contexto escolar, visto que ele contempla a ideia de reciprocidades entre Ciência, Tecnologia e Sociedade, com um olhar preocupado para o uso desmedido da tecnologia pelos seres humanos.

Este olhar passa a ser projetado para elaborar, desenvolver e refletir sobre a implantação de temas que gerem problemas de relevância social no interior do contexto escolar. Logo, o enfoque CTS diferencia-se do 
ensino tradicional, pois busca, principalmente, envolver as questões sociais nos problemas tecnológicos, isto é, passa a administrar a tecnologia para uma ação social, pois se entende que o desenvolvimento das teorias científicas pode influenciar o desenvolvimento do pensamento das pessoas.

Dessa forma, é pertinente que o enfoque CTS esteja presente em todas as disciplinas do currículo escolar. Ou seja, o enfoque CTS pode ser combinado com as demais abordagens metodológicas do processo de ensino e aprendizagem, pois essa combinação promove uma ruptura da abordagem metodológica tradicional, assim como promove uma motivação para a aprendizagem e desenvolve nos educandos a criticidade para avaliar os aspectos sociais e ambientais oriundos da tecnologia ou do uso de ferramentas tecnológicas.

Bazzo e Cury (2001) afirmam que, dessa forma, os educandos podem edificar um juízo mais real da natureza social da Ciência e da Tecnologia, bem como o entendimento desses aspectos os promoverá, gradualmente, a detectar o uso não crítico das ciências e, assim, assumir ações sobre os problemas reais de seu dia a dia. Pois, os educandos devem estar aptos a identificar problemas e resolvêlos, a elaborar modelos e interpretar dados; a comunicar-se eficientemente nas formas escrita, oral e gráfica; a avaliar o impacto da atividade e o papel do profissional no contexto social e ambiental; a trabalhar em equipes multidisciplinares.

Estudiosos de tópicos CTS, como, por exemplo, Bazzo e Cury (2001); Cerezo (2003); Cury e Pinent (2000); Díaz (2001); Fleener (1996); Rosenthal (1989) entre outros, sugerem que o enfoque CTS seja inserido em disciplinas como no Cálculo, na Álgebra, na Estatística, relacionando a Matemática com as Ciências e a Tecnologia.

Em particular, Cury (2001) sugere que cada curso poderá enfocar diferentes temas que venham a gerar discussões. A autora ainda cita modelos matemáticos na Biologia, na Física, na Química e na Medicina, assim como o uso da Estatística na exposição de dados relacionados com a sociedade e o meio ambiente, questões éticas e políticas relacionadas com a Matemática e seu ensino, entre outros.

Para Cury (2001), o desdobramento de fatos apresentados por meio de questionamentos sobre as causas e consequências de descobertas ou invenções leva a discussões a respeito do contexto histórico e social.

\section{Discutindo o Caminho Percorrido}

Este trabalho, com enfoque CTS, apresenta o desenvolvimento de atividades que exploraram a conexão entre conteúdos de Matemática, Ciências, História, Geografia e Tecnologia.

Para tanto, idealizou-se o projeto "Apagão, outra vez?", que tinha por objetivo, alertar os estudantes que a energia elétrica é relevante para o modo de se viver neste século XXI.

Os sujeitos deste projeto eram 28 estudantes do nono ano do Ensino Fundamental de uma escola estadual localizada na cidade de Ponta Grossa no Estado do Paraná, que atende a comunidade específica de um bairro daquela cidade.

Cabe apontar que, no decorrer do projeto, os dados, aqui apresentados, foram coletados por meio de registros diários feitos pela pesquisadora, de registros feitos pelos estudantes e de conversas individuais e coletivas, gravadas em áudio, cuja análise tem cunho qualitativo.

Destaca-se que a implementação do projeto aconteceu em dois momentos, sendo que o primeiro deles teve, como metodologia, aulas expositivas sobre os temas: energia elétrica, potência e energia, desperdício de energia, energia elétrica gerada em hidrelétricas, estatística. O segundo, reflexões e discussões em grupo dos dados obtidos no primeiro momento. Destaca-se que o desenvolvimento dos dois momentos aconteceu no decorrer de cinco dias letivos, aqui detalhados. 


\section{- Primeiro Dia}

Inicialmente, o professor, na sua aula de Matemática, apresentou aos estudantes estudos sobre o consumo de energia no Brasil, nas últimas décadas. Um desses estudos revelou que, anualmente, o Brasil desperdiça 50 bilhões de dólares só em energia elétrica. Quase 5 bilhões de dólares se perdem em luzes desnecessariamente acesas, longos banhos, máquinas desreguladas e equipamentos obsoletos. Devido à estabilidade da economia no país, até meados de 2008, houve um aumento na produção e no consumo de eletrodomésticos, causando um aumento rápido e não previsto no consumo de energia elétrica.

Essas informações despertaram a necessidade de conscientizar a população sobre o consumo racional de energia. Para tanto, os estudantes foram encaminhados ao laboratório de informática, onde realizaram uma busca na internet sobre a crise energética brasileira. Em seguida, responderam, individualmente, às atividades apresentadas no quadro 1.

Quadro 1 - Atividades apresentadas aos estudantes no primeiro dia do projeto

- Procure em jornais on-line, textos sobre o "apagão" que o Brasil sofreu no ano de 2000. Então, faça um texto resumo com as informações encontradas.

- $\quad$ No site www.copel.com procure as "contas" de luz de sua casa dos meses de maio, junho e julho do ano de 2000.

Então, faça o cálculo da média do consumo de sua família nesses três meses.

- O Governo Federal separou as contas de luz do ano de 2000 de todas as famílias. Então, calculou quanto cada família gastou em maio, junho e julho de 2000, fazendo uma média do consumo (soma de três contas, divididas por três). Depois, o governo Federal, com essa média em mãos, decidiu que, em 2001, todo consumidor de energia elétrica teria que gastar 20\% menos energia que gastou nesses três meses de 2000. Procure no site www.copel.com, as "contas" de luz de sua casa de 2001 e verifique se sua família conseguiu economizar os $20 \%$ solicitados pelo governo. Para isso, faça o seguinte: confira mês a mês o consumo faturado e calcule se ele ficou $20 \%$ menor que a média de consumo de sua família nos três meses de 2000 .

- O Brasil é muito grande. Então, verifique se todos os estados brasileiros fizeram parte desse racionamento de energia elétrica.

Fonte: Do próprio autor.

Os estudantes, após terem resolvido as atividades propostas no quadro 1, passaram a sociabilizálas com os colegas. Nesse momento, surgiram discussões de como suas famílias participaram e conseguiram atingir as metas do governo, colaborando para evitar os apagões.

Durante essa sociabilização, apareceram diversos comentários, dentre os quais, se destacaram os excertos dos estudantes A. P., R. E., S. T. V., A. K., O. S. e T. M. R.

A energia elétrica é fundamental para nossa vida. Porém, só percebemos sua importância quando ela "falta" (Estudante A. P.).
Quando o fornecimento de energia elétrica é interrompido por algum motivo, minha "casa" não funciona (Estudante R. E.).

Qual não deve ter sido a surpresa das pessoas ao se deparem, da noite para o dia, com uma crise energética de dimensões tão grande (Estudante S. T. V.).

É preciso nos conscientiza que a energia pode acabar a qualquer momento e novo "apagão", pode trazer dias escuros (Estudante A. K.).

Muito legal saber que cada Estado brasileiro tem consumo e produção de energia elétrica tão diferente (Estudante O. S.). 
Estou tão acostumado a ter energia elétrica em casa. Não sei se saberia viver sem ela (Estudante T. M. R.).

De um modo geral, os estudantes A. P., R. E., S. T. V., A. K., O. S. e T. M. R. demonstraram não terem conhecimento do apagão ocorrido no ano de 2000. Também, demonstraram surpresa ao imaginarem suas vidas sem energia elétrica.

Bazzo (1998, p. 142) destaca que é:

[...] inegável a contribuição que a ciência e a tecnologia trouxeram nos últimos anos. Porém, apesar desta constatação, não podemos confiar excessivamente nelas, tornando-nos cegos pelo conforto que nos proporcionam cotidianamente seus aparatos e dispositivos técnicos. Isso pode resultar perigoso porque, nesta anestesia que o deslumbramento da modernidade tecnológica nos oferece, podemos nos esquecer que a ciência e a tecnologia incorporam questões sociais, éticas e políticas
Desse modo, assinala-se a pertinência de uma formação de um homem com um perfil diferenciado, com uma visão crítica e criativa para as coisas do mundo, com uma atitude de cooperação, de realização e de tomada de decisões de maneira rápida e acertada.

\section{- Segundo Dia}

A segunda aula do projeto teve início com a leitura coletiva do texto "A conta de luz e os watts", extraído do livro "Vivendo Ciências" (SALÉM; CISCATO; LUZ, 2002, p. 105-107).

Na sequência, foi proposto que os estudantes se reunissem em equipe para realizarem as atividades apresentadas no quadro 2.

Quadro 2 - Atividades apresentadas aos estudantes no segundo dia do projeto

- Sociabilizar as dúvidas do texto com os colegas da equipe e explicar entre si o que entenderam.

“[...] o Brasil tem potencial para produzir pelo menos 15 mil megawatts por hora de energia a partir de fontes alternativas. Somente nos Estados da região Sul, o potencial de geração de energia por intermédio das sobras agrícolas e florestais é de 5.000 megawatts por hora. Para se ter uma ideia do que isso representa, a usina hidrelétrica de Ita, uma das maiores do país, na divisa entre o Rio Grande do Sul e Santa Catarina, gera 1.450 megawatts de energia por hora.” (ENEM, 2001, questão 47).

Esse texto, transcrito de um jornal de grande circulação, contém, pelo menos, um erro conceitual, ao apresentar valores de produção e de potencial de geração de energia. Descubra esse erro e reescreva o texto corretamente. Então, apresente o texto com as correções feitas por você para seus colegas usando o Datashow.

Fonte: Do próprio autor.

No decorrer do desenvolvimento das atividades apresentadas no quadro 2, os estudantes teceram diversos comentários, dos quais, são relevantes para este estudo, os excertos dos estudantes I. S. S., S. D., V. G. e A. P.

A potência indica o consumo e o fornecimento de energia elétrica em um circuito de corrente alternada (Estudante I. S. S.).

O conceito de potência aplica-se também quando um corpo está recebendo ou fornecendo energia (Estudante S. D.).

Quando nos referirmos a uma potência elétrica, não devemos falar "wattagem", pois ele é errado (Estudante V. G.).
Eu nem imaginava que aqueles $k W$ que aparecem na conta de luz lá de casa vale tudo isso: $1 \mathrm{~kW}=1$ quilowatt $=103$ watts $=103 \mathrm{~W}$ (Estudante A. P.).

Cabe relatar que, com o exposto nos excertos dos estudantes I. S. S., S. D., V. G. e A. P., estes passaram a se interessar pelos termos técnicos apresentados no texto "A conta de luz e os watts", extraído do livro Vivendo Ciências (SALÉM et al., 2002). E, também, começaram a descrever algumas propriedades informalmente, o que poderá facilitar a aprendizagem formal desses estudantes no Ensino Médio, principalmente, no que toca aos conteúdos de Física. 
Segundo Rosenthal (1989), o conteúdo referente às Ciências do currículo de CTS incluem, assim, aspectos relativos a estudos políticos de Ciência, mais vinculados às questões sociais externas à comunidade científica, como por exemplo, a conservação de energia, crescimento populacional, efeitos da energia, entre outros.

\section{- Terceiro Dia}

$\mathrm{Na}$ terceira aula do projeto, foi apresentado aos estudantes o texto "Como é feita a leitura no relógio de luz?", extraído do livro "Vivendo Ciências" (SALÉM; CISCATO; LUZ, 2002, p.107-109). Ao término da apresentação, foi proposto que os estudantes formassem duplas para resolverem as atividades apresentadas no quadro 3 .

Quadro 3 - Atividades apresentadas aos estudantes no terceiro dia do projeto

- Façam um levantamento do consumo de energia elétrica de suas casas. Para isso, os alunos devem considerar aparelhos e/ou utensílios eletroeletrônicos que têm em suas casas e não se esqueçam de verificar quanto tempo eles ficam ligados. Divirtam-se e descubram quanto suas famílias gastam para pagar a fatura de energia elétrica.

- A COPEL tem, em seu site www.copel.com, o portal - COPEL Conforto - que simula o consumo de energia elétrica, mesmo sem tê-la usado. Usem esse simulador do consumo de energia elétrica e descubram a relação consumo/preço de energia elétrica que alguns aparelhos domésticos têm. (COPEL, 2008).

Fonte: Do próprio autor.

Os estudantes, depois de terem concluído as atividades apresentadas no quadro 3, sociabilizaram, com os demais colegas, as respostas encontradas. Nesse momento, alguns estudantes teceram comentários sobre dados encontrados com o desenvolvimento das atividades. Dentre esses comentários, destacaram-se os excertos dos estudantes A. P., M. A. R., L. L. P. e M. N.

Não sabia que a impressora consume tanta energia (Estudante A. P.).

Coitado do meu pai para pagar o que eu e minha irmã desperdiçamos (Estudante M. A. R.).

Eu nem imaginava que no Brasil há um consumo muito grande de energia elétrica no período das 18 às 21 horas, devido ao fato em que as pessoas chegarem em suas casas e ligarem lâmpadas, chuveiros, TV, causando sobrecarga no sistema de fornecimento de energia (Estudante L. L. P.).

Até que enfim um trabalho que mostra a nossa realidade (Estudante $\mathrm{M}$. N.).

De um modo geral, os excertos dos estudantes A. P., M. A. R., L. L. P. e M. N. permitem afirmar que os sujeitos deste estudo se interessaram com o uso do portal - COPEL Conforto - pois, nele, puderam fazer diversas simulações a respeito do consumo de energia elétrica nos vários eletrodomésticos que o portal apresenta. Também, mostraram-se surpresos ao verificar o consumo mensal e o custo das lâmpadas que possuem em suas casas. (COPEL, 2008).

Destaca-se que, nesse terceiro dia da implementação do projeto, o estudante I. K. encontrou no site da COPEL um texto sobre a criação do Selo PROCEL de Economia de Energia, instituído pelo Decreto Presidencial de 08 de dezembro de 1993. Esse estudante, empolgado, explicou para seus colegas que esse selo.

Tem por objetivo orientar o consumidor no ato da compra, indicando os produtos que apresentam os melhores niveis de eficiência energética dentro de cada categoria (Estudante I. K.).

Diante da explicação do estudante I. K., os demais se interessaram em saber mais sobre o Selo PROCEL de Economia de Energia e expressaram interesse de verificar, nos eletrodomésticos de suas residências, a existência do mesmo. 
Para Cerezo et al. (2003, p. 144), a relevância do enfoque CTS para educação visa "à alfabetização para propiciar a formação de amplos segmentos sociais, de acordo com a nova imagem da Ciência e da Tecnologia que emerge ao ter em conta seu contexto social".

\section{- Quarto Dia}

No quarto dia da implementação do projeto, os estudantes foram divididos em dois grandes grupos, para realizaram a leitura do texto "A Física e o meio ambiente" extraído do livro "Ciências e Educação Ambiental” (CRUZ, 1998, p. 244-247), de modo que a leitura do texto foi separada em duas partes e cada grupo recebeu apenas uma dessas partes. Após a leitura da parte do texto que coube a cada grupo, estes foram convidados a escrever um pequeno resumo, com o intuito de repassarem, para o outro grupo, o conteúdo de sua parte do texto.

Com a escrita do resumo concluída, os grupos trocam os textos e, nesse momento, foi dado um tempo de 10 minutos para os estudantes refletirem individualmente sobre o texto. Então, foram encaminhados ao laboratório de informática para começarem as atividades apresentadas no quadro 4.

Quadro 4 - Atividades apresentadas aos estudantes no quarto dia do projeto

- Pesquise na internet e responda: A hidrelétrica de Itaipu é binacional. O que significa isso?

- A Itaipu, até pouco tempo, era a maior hidrelétrica do planeta. Hoje, outra hidrelétrica tomou seu lugar. Descubra o nome e a localização dessa nova hidrelétrica.

- Você sabia que, em 1999, a Companhia Paranaense de Energia, COPEL, publicou o mapa do potencial eólico do estado do Paraná? Para sua construção, foram utilizados dados de vento de cerca de vinte estações anemométricas para simulações em modelo atmosférico de microescala. Para melhor saber, pesquise sobre esse mapa e faça uma maquete dele.

- Reúna-se com outros dois colegas e façam uma pesquisa na internet, para obterem melhores informações de como as fontes alternativas de energia: nuclear, geotérmica, marés e fotovoltaica, são produzidas e o quanto elas podem contribuir para amenizar a crise energética.

Fonte: Do próprio autor.

Com as atividades expostas no quadro 4 resolvidas, os estudantes passaram a elaborar um relatório sobre as informações que descobriram. Nesse momento, alguns estudantes apontaram comentários sobre as atividades propostas. Dentre esses comentários, destacaram-se as falas dos estudantes A. N., P. T., I. B., H. M., C. M. S., C. D., G. D. S. e M. A.

É muito legal a forma como a energia elétrica é produzida. Eu não imaginava que a energia potencial que a água tem na parte alta da represa é transformada em energia cinética, e faz com que as pás da turbina girem, fazendo funcionar o eixo do gerador, produzindo a energia elétrica (Estudante A. N.).

Agora sei que é devido ao tipo do relevo do Brasil que as usinas hidrelétricas são a principal fonte de energia (Estudante P. T.).
Eu quero fazer parte dos que estão estudando fontes alternativas de energia (Estudante I. B.).

No Brasil energia térmica é o segundo tipo de fonte de energia que está sendo utilizado (Aluno H. M.).

Eu não sabia que a energia eólica é produzida pela transformação da energia cinética dos ventos em energia elétrica (Estudante C. M. S.).

O Brasil produz e exporta equipamentos para usinas eólicas, mas elas ainda são pouco usadas. Tem usina que produz energia eólica em Minas Gerais, no Ceará e em de Fernando de Noronha (Estudante C. D.).

Enquanto não temos fontes alternativas de energia, precisamos economizar a energia elétrica. A partir de hoje, vou fechar a torneira d'água quando estiver me ensaboando (Estudante G. D. S.).

Vou pedir para o meu pai trocar as lâmpadas lá de casa para lâmpadas fluorescentes (Estudante M. A.). 
De modo geral, as falas dos estudantes A. N., P. T., I. B., H. M., C. M. S., C. D., G. D. S. e M. A. demonstram que eles estavam interessados em descobrir fontes alternativas de energia, como a energia nuclear, geotérmica, fotovoltaica, mais conhecida como energia solar, entre outras.

Também, é relevante apontar que os estudantes procuraram em sites diversos sobre essas fontes alternativas de energia, pois, com esse novo conhecimento, eles podem vir a desenvolver estudos de conscientização sobre a economia de energia elétrica, enquanto essas fontes alternativas não se fazem muito presentes no Brasil.

Layton (1988) afirma que, na perspectiva de formar um cidadão apto a compreender como a tecnologia tem influenciado o comportamento humano e desenvolver atitudes em prol de um desenvolvimento tecnológico sustentável, é essencial que haja uma discussão dos valores envolvidos nas decisões.

Corroborando com Layton (1988), Boff (1996) relata que é a partir da identificação dos valores que se compreendem melhor as necessidades da sociedade e os aspectos éticos que devem ser considerados no uso mais responsável da tecnologia.

\section{- Quinto Dia}

No último dia da implementação do projeto, os estudantes foram encaminhados à biblioteca da escola, com o objetivo de consultar, em livros didáticos de Matemática, os conceitos estatísticos: média, moda e mediana.

Após a conclusão da consulta, foram esclarecidas as dúvidas sobre os conceitos estatísticos pesquisados com o professor de Matemática.

$\mathrm{Na}$ sequência, os estudantes se deslocaram para o laboratóriodeinformáticaeiniciaramodesenvolvimento das atividades apresentadas no quadro 5.

Quadro 5 - Atividades apresentadas aos estudantes no quinto dia do projeto

- Verifique como anda o consumo e/ou o desperdício de energia em sua casa, atualmente. Pegue a última "conta" de luz de sua casa - você já sabe onde encontrar essa conta - para responder, calcular, pensar e economizar!!!

a) Veja qual foi o valor do consumo faturado em $\mathrm{KWh}$ e o valor do consumo médio diário.

b) Qual o valor cobrado hoje pela COPEL pelo KWh, em reais?

c) Qual o valor da taxa de iluminação pública?

d) Usando o excel, construa um gráfico com os dados dos 12 meses de consumo de energia elétrica de sua casa. O gráfico pode ser de colunas ou de linhas, você decide.

e) Calcule a média de consumo de energia elétrica dos últimos 12 meses de sua casa. Faça o cálculo no caderno, depois confira o resultado, usando os recursos do excel.

f) Houve moda durante esse período? Se houve, qual foi?

g) Determine a mediana nesse mesmo período. Novamente, faça o cálculo no caderno, depois confira o resultado, usando os recursos do excel.

h) Agora, compare o consumo de energia atual de sua casa com o consumo de 2001 e verifique se ele aumentou, diminuiu ou ficou igual.

- Entre em contato com a Eletrobrás, usando o site www.eletrobras.com, e pergunte qual é o consumo médio diário de energia elétrica em nosso país.

Fonte: Do próprio autor. 
Após resolverem as atividades apresentadas no quadro 5, os estudantes passaram a escrever um relatório sobre as informações que encontraram. No decorrer dessa escrita, eles externaram diversos comentários, dentre os quais, se destacaram os comentários dos estudantes A. P., I. V. e S. D.

Meu Deus! Até hoje a crise energética não foi resolvida. Está como um vulcão adormecido, a qualquer momento entrará em erupção novamente (Estudante A. P.).

Mesmo sem “apagão" precisamos economizar energia, para também poupar dinheiro (Estudante I. V.).

Bem que minha mãe diz: "luz que se apaga não se paga” (Estudante S. D.).

Os comentários dos estudantes A. P., I. V. e S. D. no decorrer do desenvolvimento das atividades apresentadas no quadro 5, passaram a compreender que a energia elétrica pode faltar novamente. E, se isso ocorreu, um caos acontecerá. Assim, acreditase que os estudantes passaram a perceber que os conteúdos aprendidos na escola tem utilidade em sua vida social.

Segundo Pinheiro, Silveira e Bazzo (2007, p. 73),

A capacidade de entender a realidade, de colocar-se no mundo de uma forma mais ativa, a capacidade de compreender criticamente uma notícia, de ler um texto científico, de entender e avaliar questões de ordem social e política e a se posicionar frente os desafios e as questões mais emergenciais do mundo, constituem os conhecimentos e as habilidades mínimas necessárias para que os indivíduos possam ser alfabetizados científica e tecnologicamente dentro de uma abordagem social.

Logo, o desenvolvimento de uma educação científica e tecnológica, dentro de uma perspectiva social, dever estar inserida em um contexto mais amplo de discussões, levando a debates e ao domínio público as contribuições, tanto positivas, quanto os impactos negativos da utilização desmedida da Ciência e da Tecnologia.

\section{Conclusões}

Apesar do cenário de mudanças, de transformações e inúmeras descobertas científicas e tecnológicas que o mundo perpassa, existem questões emergenciais que se apresentam ao homem a cada dia, que precisam ser pensadas e revisitadas.

Nesse contexto, a problemática levantada neste trabalho está relacionada com um tema atual e de abrangência mundial. Logo, representa um desafio para os países em desenvolvimento, como o Brasil.

De modo geral, as atividades realizadas no projeto "Apagão, outra vez?" foram relevantes, pois permitiram uma reflexão sobre a vivência do estudante, enfocando os conceitos de energia envolvidos no seu dia a dia. Pois, os conteúdos propostos apresentaram grau de complexidade e abordagem adequada aos sujeitos e podem ser aprofundados pelos educadores durante a realização das atividades propostas. O que permitirá que professores de outras áreas do saber se apropriem dessa atividade e a desenvolver com objetivos próprios de seu conteúdo.

Bem se sabe que, nos dias atuais, é de suma importância que todos tenham consciência dos problemas sociais, para, junto aos alunos, encontrar caminhos que contribuam para a melhoria desses problemas.

Assim, acredita-se que a sala de aula pode trazer contribuições para a inserção crítica do cidadão no mundo em que vive, e que a escola tem um importante papel a desempenhar nesse processo.

Dessa forma, a educação tecnológica deve estabelecer a interação dos conteúdos e das disciplinas, por meio dos questionamentos dos "porquês" da Tecnologia. E, com esses questionamentos, fornecer subsídios para a construção do saber e do ensinar a aprender para, assim, formar cidadãos responsáveis e socialmente conscientes.

\section{Referências}

BAZZO, W. A. Ciência, tecnologia e sociedade: e o contexto da educação tecnológica. Florianópolis: Ed. da UFSC, 1998. 
BAZZO, W. A. et al. Introdução aos estudos CTS (Ciência, Tecnologia e Sociedade). Madrid: Organização dos Estados Iberoamericanos, 2003.

BAZZO, W. A.; CURY, H. N. Formação crítica em matemática: uma questão curricular? Bolema, Rio Claro, v. 14, n. 16, p. 29-47, 2001.

BOFF, L. Ecologia: grito da terra, grito dos pobres. 2. ed. São Paulo: Ática, 1996.

CEREZO, J. A. L. et al. Introdução aos estudos CTS (Ciência, Tecnologia e Sociedade). Madrid: OEI, 2003.

COMPANHIA PARANAENSE DE ENERGIA COPEL. Conforto. 2008. Disponível em: <http:// www.copel.com/hpcopel/root/nivel2.jsp?endereco $=\% 2$ Fhpcope $\% 2$ Froot $\% 2$ Fpagcopel $2 . n s f \% 2 F 0 \% 2$ F534c75cd39b6db52032573f70041eb5f>. Acesso em: 25 jun. 2012.

CRUZ, D. Ciência e educação ambiental. São Paulo: Ática, 1998.

CURY, H. N.; PINENT, C. E. C. Análise de atitudes de calouros de engenharia em relação às ciências e à matemática. Revista de Ensino de Engenharia, São Paulo, v. 19, n. 1, p. 47-54, ago. 2000.

DÍAZ, J. A. A. Una breve revisión de las creencias CTS de los estudiantes. 2001. Disponível em: $<$ http://www.campus-oei.org/salactsi/acevedo. htm>. Acesso em: 7 maio 2012.

EXAME NACIONAL DO ENSINO MÉDIO ENEM. Prova amarela. 2001. Disponível em: $<$ http://download.inep.gov.br/educacao_basica/ enem/provas/2001/2001_amarela.pdf.>. Acesso em: 10 jun. 2012 .

FLEENER, M. J. Scientific world building on the edge of chaos: high school students beliefs about mathematics and science. School Science and Mathematics, Menasha, v. 96, n. 6, p. 312-320, 1996.

LAYTON, D. Revaluing the T in STS. International Journal of Science Education, London, v. 10, n. 4, p. $367-378,1988$.

MARCUSE, H. Tecnologia, guerra e fascismo. São Paulo: Ed. UNESP, 1999.

MARX, K. O capital: crítica da economia política.

São Paulo: Difel, 1984.
PINHEIRO, N. A. M.; SILVEIRA, R. M. C. F.; BAZZO, W. A. Ciência, tecnologia e sociedade: a relevância do enfoque CTS para o contexto do ensino médio. Ciência \& Educação, Bauru, v. 13, n. 1, p. 71-84, abr. 2007.

ROSENTHAL, D. B. Two approaches to science: technology: society (STS) education. Science Education, Salem, v. 73, n. 5, p. 581-589, 1989.

SALÉM, S.; CISCATO, C. A. M.; LUZ, M. L. Vivendo ciências. São Paulo: FTD, 2002. (Livro didático, $8^{\mathrm{a}}$ Série).
Recebido em: ago. 2012 Aceito em: dez. 2012 